THE USE OF STATISTICAL METHODS IN EFFECTING IMPROVEMENTS ON A JONES SAMPLE SPLITTER

BY

GEORGE H. OTTO

Reprinted from Sedimentary Petrology for December, 1937 


\title{
THE USE OF STATISTICAL METHODS IN EFFECTING IMPROVEMENTS ON A JONES SAMPLE SPLITTER*
}

\author{
GEORGE H. OTTO \\ Soil Conservation Service, Cooperative Laboratory, California Institute of Technology, \\ Pasadena, California
}

\begin{abstract}
An improved Jones sample splitter is described which is faster to operate than the conventional type, yet requires no special skill or training. Samples obtained with this instrument are free from the occasional erratic samples obtained with ordinary Jones sample splitters. Working drawings are given for this improved sample splitter, which can be built with hand tools.

The sample splitter was tested with small gravel, granules, and sand in which the percentage of each constituent was accurately known. Three series of 24 samples each were taken and sieved; in each series one detail of technique was varied. The components separated by sieving were returned to the original mixture in each test to keep the conditions of the experiment nearly constant. Summarized instruction are given for the best technique of operation.

The second part of the paper deals with methods used to measure the performance of the improved sample splitter. The concept of a state of control is discussed. The calculations required to detect lack of constancy in the chance cause system, biased percentages, or the presence of a predominating cause of variation are shown. The principle that variability in comparable series of samples tends to diminish as the state of control is approached was found to apply in the present study.

These methods of statistical analysis are very general and may be applied to field sampling studies or wherever quantitative measurements are made on a series of samples suspected of coming from an essentially homogeneous unit or constant chance cause system.
\end{abstract}

\section{PART I-INTRODUCTION}

The Cooperative Laboratory of the Soil Conservation Service at California Institute of Technology carries on frequent hydraulic experiments which involve the mechanical analysis of sediments. Often a small change in composition is known to have occurred. A quantitative knowledge of the errors involved is required. The quantity of sediment is such that "field" errors are of the same order of magnitude as laboratory errors. Effective study of the sampling errors demands that the laboratory errors be known. Consequently, the sample splitting prob- lem was selected for detailed study. Mining engineering literature contains numerous references to various devices (7) for obtaining representative samples of ores for chemical analysis. Most of these devices include moving parts and were developed for continuous sampling of streams of ore coming from crushers. They are usually operated in tandem, the sample being crushed between each successive reduction. Such devices as the Vezin sampler (1) and the Brunton timesampler $(2,3)$ are typical of those intended for continuous feeds. They employ the principle of taking "all the stream part of the time."

* Published with permission of the Soil Conservation Service, U. S. Dept. of Agriculture. 
No record of extensive tests was found in any of the references describing the Jones sample splitter (9) or modifications of it. The theory, as it applies to ore sampling, is discussed by Brunton (4). Sampling for mechanical analysis offers a difficulty not encountered in mining sampling: the sample cannot be crushed at any stage of the reduction. This difficulty may be overcome by choosing a field sample with a number of particles just large enough to represent the rarest or coarsest component under study. Wentworth discusses this procedure (12). Laboratory sampling and sieving errors also were investigated by Wentworth (13).

The sample splitting plan used by Wentworth differs from the practice of most operators who habitually interchange the contents of the pan on the right side with the just emptied pouring pan or scoop. Consequently, it seems preferable in a study of different techniques of operation, or of the efficiency of two or more instruments, to take each sample in exactly the same manner. Furthermore, it is desirable that the sieved material be replaced before the next sample is split off. The resulting variability, if enough samples are taken, is then a reliable measure of the amount of deviation from the average to be expected in single samples of similar sediments.

CHARACTERISTICS OF AN EF-

FICIENT LABORATORY

SAMPLE SPLITTER

A certain amount of variation in any series of samples is to be ex- pected. Even if all the particles were the same size, shape, density, and elasticity and differed only in some characteristic such as color, the samples would not have the same percentage of particles of each color every time. But if the number of particles of each color were very large and the samples were large, the resulting percentages of each color would show little variation with almost any sample selecting device. In such cases and even for small samples it is possible to calculate, without recourse to experiment, the important mathematical properties, or statistics, of a large number of samples.

In ordinary mechanical analyses, frequencies are expressed in per cent by weight. A single extra pebble therefore has a far greater influence than a single extra sand grain. Because the particles are irregular in shape and because average shape characteristics are seldom quantitatively known, the problem of calculating the variation to be expected in a large series of samples cannot be solved without recourse to experiment. Furthermore, number frequencies are not usually a practical medium for expressing mechanical analyses because of the extraordinarily low frequencies of the coarser particles and the uncertainty regarding the total number present.

Thus for ordinary sediments efficiency cannot be measured by comparing statistics derived from experimental tests with a set of calculated values. Let an experiment be devised, however, in which all errors except the sample splitting error are 
relatively unimportant and in which the experimental set-up closely simulates conditions in practice; let measurements be made on each of a number of samples. Such data will not only furnish the basic information for determining the empirical performance characteristics of the instrument, but will also go far toward answering the question, "Can the performance be considerably improved without altering the basic principles of design or operation?" The technique of analyzing such data and the reasoning leading to the actual improvements are discussed in part II.

An efficient laboratory sample splitter should be convenient to operate and should give dependable results under a wide variety of conditions. These characteristics may be classified as follows:

\section{A. Performance characteristics}

1. If some quantitative measurement be made on each of a large number of samples, and if the errors of the measurement are small compared with the sampling errors, the number of values lying within a symmetric range of the average value (arithmetic mean) should be predictable. The symmetric range is ordinarily expressed as some multiple of the standard deviation ${ }^{1}$ of the values.

The practical importance of this property of an efficient sample splitter is as follows: Suppose that one laboratory sample is split off from each of two field samples (part of a suspected variation series), and that the two

1 The standard deviation, denoted by $\sigma$, is defined by the equation

$$
\sigma=\sqrt{\frac{\sum(X-\bar{X})^{2}}{N}}
$$

where $(X-\bar{X})^{2}$ is the square of the deviation of an observed value, $X$, from the arithmetic mean value of the group and $N$ is the number of measurements. samples show a small difference in some measured characteristic. If an estimate is available for the standard deviation of this characteristic in samples obtained with the sample splitter, it is possible to say whether the difference may reasonably be attributed to sampling fluctuations alone. If it is known, however, that the distribution of a large number of samples is not approximately predictable, limits to the fluctuations cannot be assigned with any assurance.

2 . The average value of any measurable characteristic determined for each of a series of samples should approach the true value as the number of samples is increased.

3. Different operators should obtain essentially the same average values.

4. Different operators should obtain essentially the same dispersion of values about their averages.

5. The materials to be sampled must not tend to clog the instrument.

\section{$B$. Convenience characteristics}

1. The sample splitter should be capable of handling dry gravel passing a $16 \mathrm{~mm}$. sieve and all smaller sizes of dry material. An instrument capable of handling coarser material is too unwieldy for small samples of fine sands.

2. The pans should hold approximately four kilograms of sand. Larger capacities make the pans hard to manipulate; smaller capacities are insufficient for pebbly sands and fine gravels, even after removing the coarsest sizes from the entire field sample.

3 . No special training or skill should be required.

4. The sample splitter should be ruggedly constructed and preferably free from moving parts.

5. The design should prevent unnecessary losses.

6. The instrument should be capable of rapid operation and easy cleaning.

7. An instrument which can be built from readily available materials and ordinary hand tools is desirable.

CONSTRUCTION OF THE IMPROVED

JONES SAMPLE SPLITTER

A study of many types of sample splitters showed that those with 
moving parts are not well adapted to the intermittent feeds and small samples necessarily encountered in the last stages of sample reduction. The Jones type seemed to offer the most promise, despite an inherent defect in the method of taking the sample: it belongs to that class of sample splitters which take "part of the stream all of the time." This of chutes, usually 12 to 18 , and allowing the streams from alternate chutes to be included in the sample. One abnormal end-fraction goes to each side. Each passage through the instrument reduces the sample to onehalf the previous size.

The sample splitter shown in fig. ure 1 was used in all the later experiments and will be called the im-

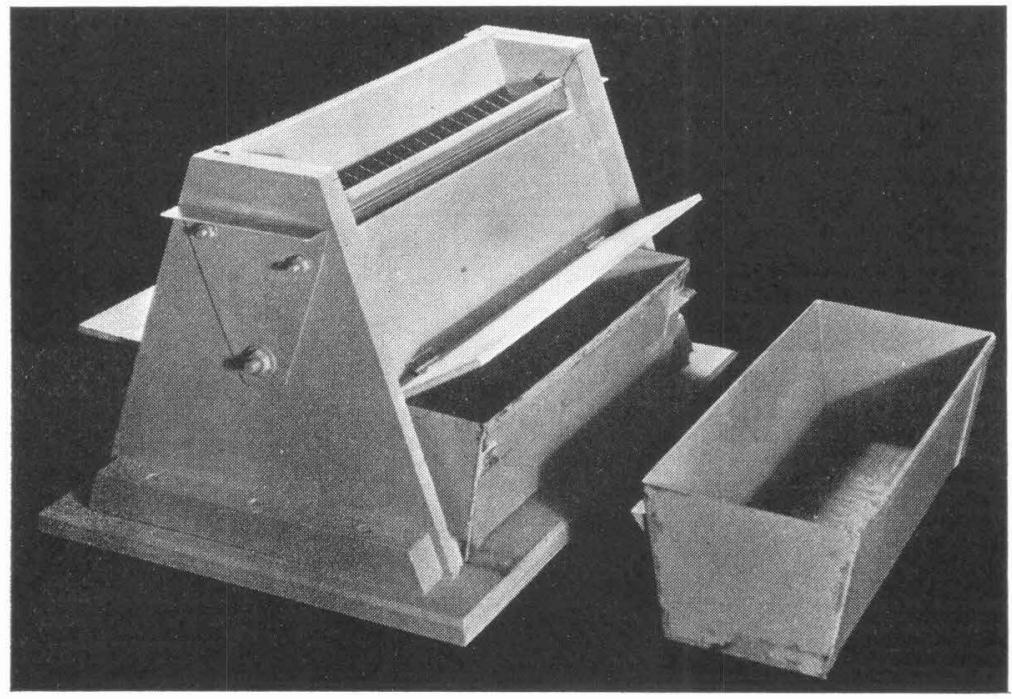

Fig. 1.-Improved Jones sample splitter.

principle is considered inferior to that used in the Vezin and Brunton samplers because the necessary divisors produce marked segregations in the stream of material passing by them. A slight injury to the divisor, or a defect in the construction, or a piece of fibrous material accidentally lodged on a divisor may divert too many coarse particles to one side. The Jones splitter minimizes this error by introducing an even number proved sample splitter. It has proved thoroughly satisfactory for a variety of sediments and conforms to the requirements outlined above.

The instrument consists of the splitter proper and three identical pans. No scoop is required. The manner of operation is essentially the same as for the Taylor and Brunton sample splitter (3). Although it differs from the conventional Jones sample splitter in appearance, the 


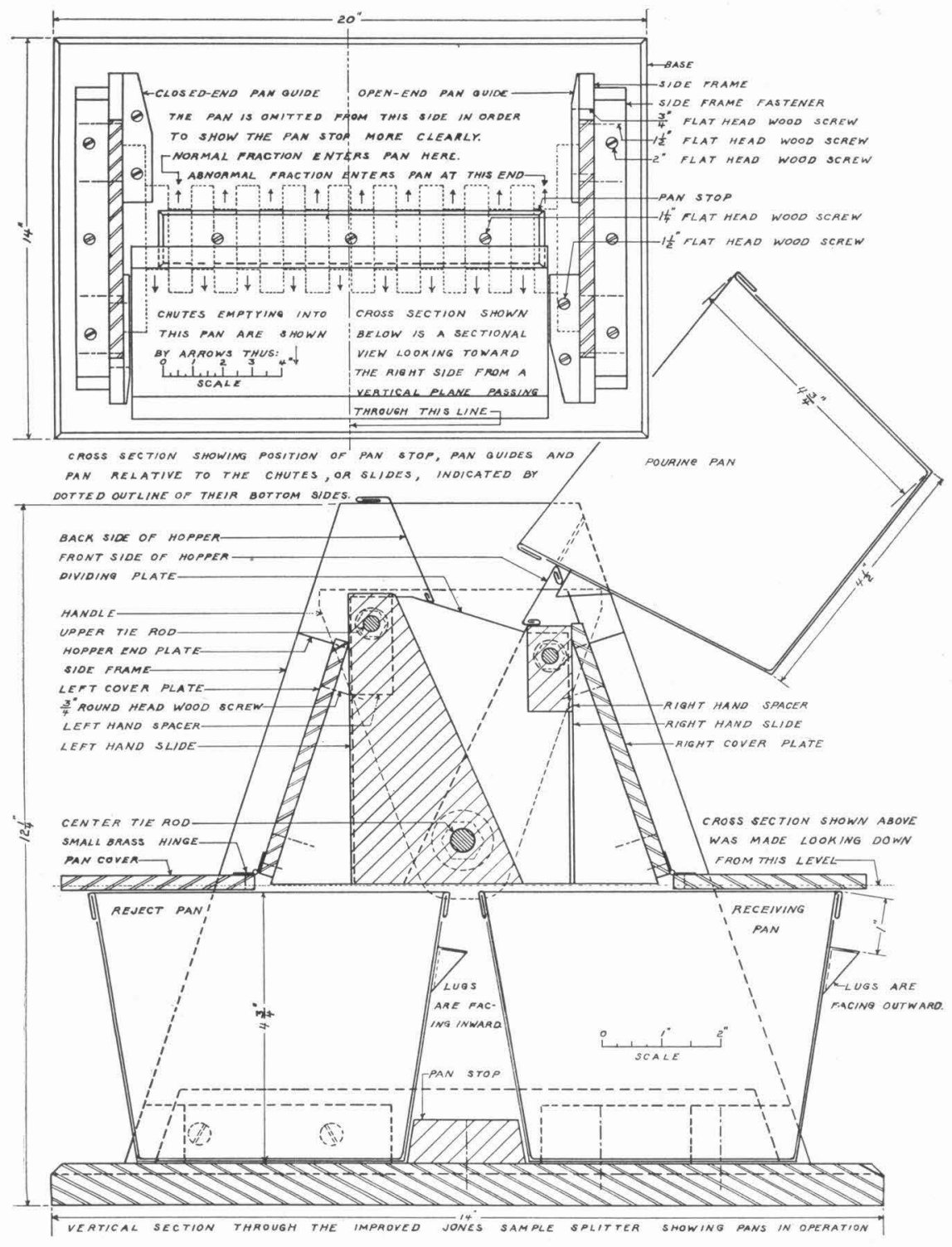

Fig. 2.-Assembly drawing of improved Jones sample splitter. 


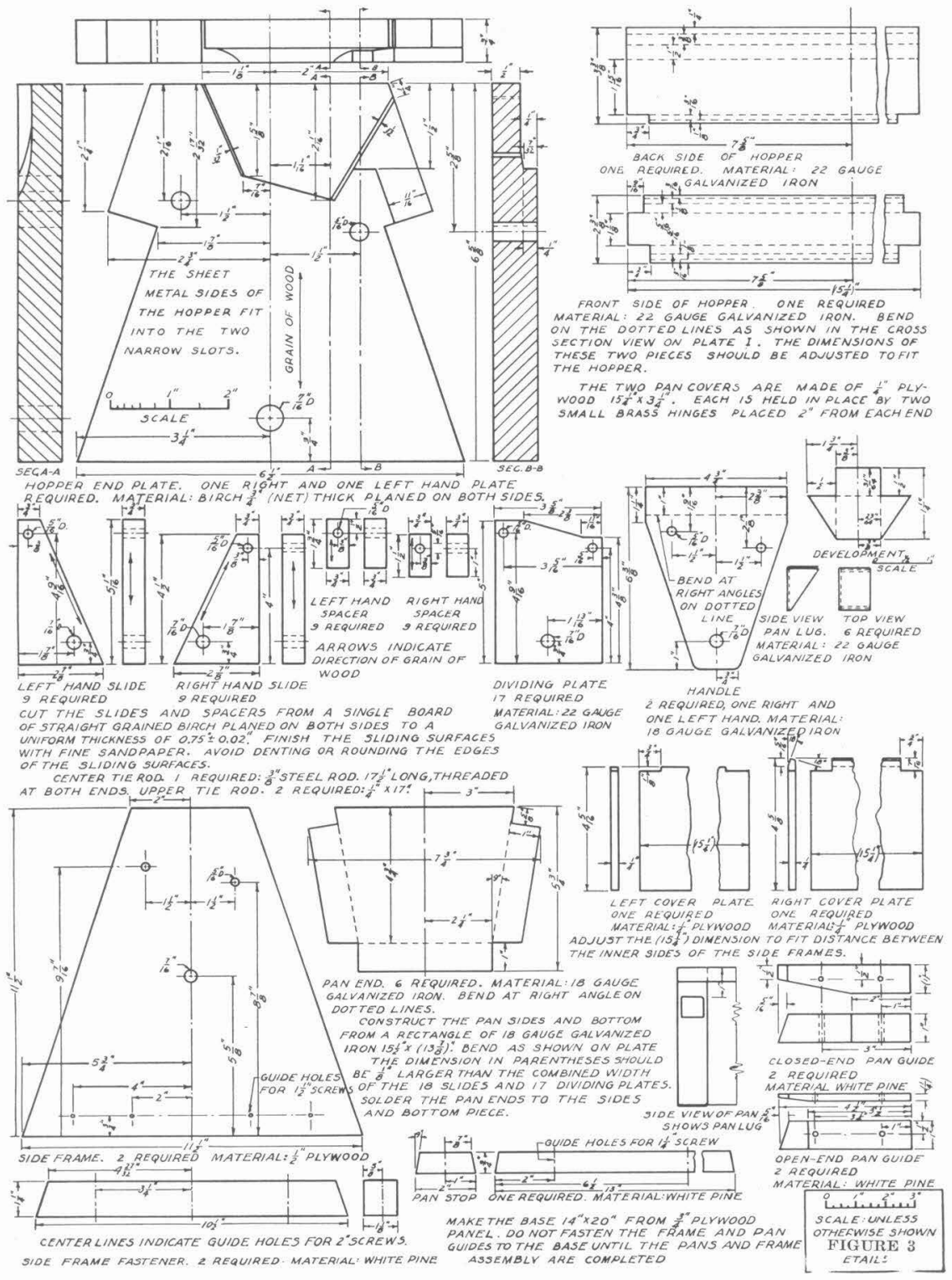

FIG. 3.-Details of construction of the improved Jones sample splitter. 
principle of operation is the same.

The improved sample splitter possesses a number of refinements which eliminate errors and greatly reduce the personal element in the operation. Figure 2 shows a cross section through the middle with the pans in operating positions. The designations used in the text for referring to the different pan positions are shown. Figure 3 shows detail drawings of the parts.

The pans are constructed of 18-gauge galvanized iron with reinforced pouring edges. Guide lugs are provided at each end of one side. The pouring pan is placed with the top side of these lugs against the lower hopper rim; in this way the pouring edge is always at right angles to the dividing plates and the pan is always emptied from exactly the same place and side. The overall width of the pans is one-fourth inch longer than the combined width of the chutes and dividing plates. The pans fit closely in the hopper and so are always correctly centered.

The splitter consists of a short hopper section, chutes called slides, partitions called dividing plates, a frame, and receiving pan spacers.

The end plates of the hopper section are made of birch. The irregular shape provides clearances for the pans and a support for the dust covers. The front and back sides of the hopper are made of 22-gauge galvanized iron. The front side of the hopper serves as a pan rest. It is purposely built close to the dividing plates, just high enough to provide safe clearances.

Taller hoppers raise more dust and cause more wear on the sliding surfaces; gravel tends to injure the dividing plates because of stronger impacts. Tall hoppers also give the grains more opportunity to sort when there is any irregularity in the method of sample introduction. Nearly all commercial splitters have a much higher hopper, not for holding material, but presumably to serve as a mixing chamber. If the sample is very poorly mixed, desirable mixing may take place; but if the pouring edge of the pan is not exactly at right angles to the dividing plates, this extra space will accentuate the tendency to throw too much coarse material to one side.

The hopper is also narrower than in most splitters. As a result, the back side of the dividing plates had to be raised and the chutes sloping toward the pouring side had to be made steeper than the others to prevent certain sizes of grains rebounding into the other chutes. The improved splitter eliminates this error completely.

The chutes or slides are made of birch of uniform thickness and planed on both sides, with the grain of the wood parallel to the sliding edge. The sliding surfaces should be smoothly finished and should have edges free from dents in order that grains will not lodge along the contact with the dividing plate.

The dividing plates forming the partitions between the chutes are made of 22-gauge galvanized iron with the dividing edges sharpened somewhat. They show little wear after long-continued use on angular gravel.

The frame is constructed of plywood with short handles of heavy galvanized iron at each end. The parts are held together by three steel rods threaded at both ends.

The receiving pan spacers are designed to space the pans automatically with equal overlap on each end of the last open chute. They should not be fastened until the pans have been completed and the rest of the instrument has been fitted to the base.

\section{TESTS ON THE IMPROVED SAMPLE SPLITTER}

The tests on the improved sample splitter were designed to eliminate sieving errors and to detect biased percentages. Two mixtures were used. Their composition and the nature of their size distribution are shown by the histograms in Fig. 4.

The coarse mixture consisted of commercial pea gravel, a granule (11) concentrate, and sand; it weighed 5.6 kilograms. 
The fine mixture consisted of a granule concentrate, coarse sand from dune ripple crests, and fine dune sand; it weighed 4.3 kilograms.

The six parent materials were screened to remove particles outside the desired ranges, were washed to remove adhering fines, and were dried. Samples of appropriate size were split off from each of the six components and were analyzed by sieving, using a complete set of sieves. All of each component not used in the sieve analysis was weighed and used in the mixture.

Each of the six analyses is subject to the usual errors. But because the distributions of particle sizes in the components have almost no overlap, the percentages passing sieves located at the minimum grades can be very accurately measured from the weight of each of the three components of the mixtures. Consequently, using only the two sieves at the minimum grades and a pan, separations can be made in which the sieving error is negligible.

The use of such irregular distributions of particle sizes no doubt increases sampling difficulties. Since the purpose of the tests was to detect defects in the instrument, the use of such distributions is justified.

The components of the coarse mixture showed an extreme tendency to separate whenever the mixture was jarred or poured from one container to another. The best mixing was obtained by repeatedly pouring the sample through the splitter until only a small fraction was caught in the receiving pan. The reject pan and the pouring pan were now interchanged and the process repeated twice more. This procedure was used at the beginning of each series of runs with the coarse material. The components of the fine mixture were easily mixed by being poured four times from the end of one pan into the middle of another.
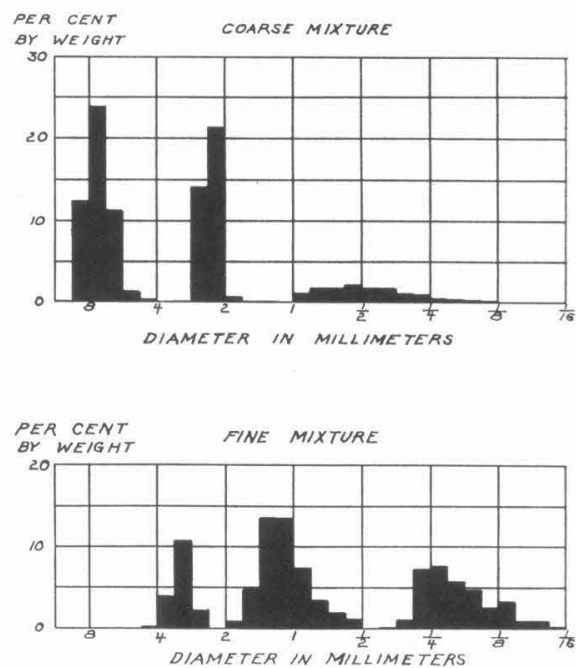

FIG. 4.-Histograms of mechanical analysis of the mixtures used in the sampling experiments.

For the coarse mixture 3 series of 24 analyses each were made as follows:

A sample one-sixteenth of the original was obtained by four passages through the splitter in the usual manner. This sample was weighed and sieved by hand shaking for about one minute. The separations were so sharp and rapid that the use of a mechanical shaker was unnecessary. Only the 3.33 and $0.991 \mathrm{~mm}$. sieves and pan were used. The weighed separates were returned before the next sample was split off.

In all cases the receiving pan was placed beneath the pouring side of the hopper. Thus 
every sample in each series was subjected to an essentially constant technique.

The first series of 24 samples was run with the receiving pan lugs facing inward at all times. The second series was run with the receiving pan lugs facing outward. The third series was run with the lugs facing alternately out and in, starting every time with the lugs out. This procedure was found to eliminate a bias which was present in both the other cases. It also decreased the dispersion in the sample weights and percentages. pan. Weighings were made to the nearest centigram. The separations were complete with only 20 seconds of vigorous shaking.

In order to obtain a measure of the improvements effected in the present design over a good commercially obtainable instrument, a series of 24 tests was run on the splitter shown in figure 5 using the fine mixture. The method of operation pic-

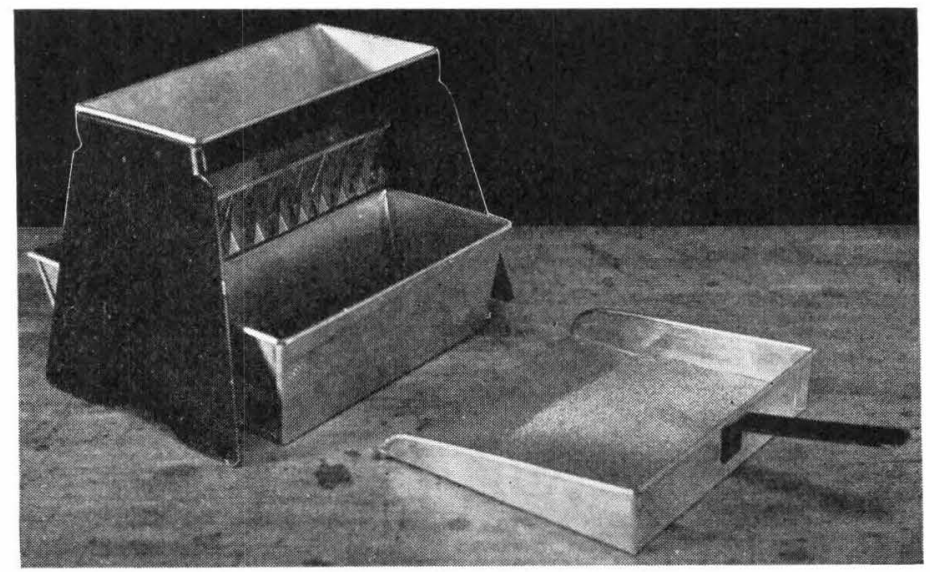

F IG. 5.-Commercial sample splitter used in tests.

The pan used to collect the rejected portion of the sample was placed with lugs facing inward at all times. Because this pan becomes the pouring pan at the start of the next sampling operation, it was desirable to keep the same arrangement of the particles relative to the pouring side. In ordinary work, where only a single sample is taken, either way is equally satisfactory.

Only one series of 24 analyses was run using the fine mixture. The lugs on the receiving pan were placed outward; a bias resulted which was much smaller than with the coarse material. All the measures of variation showed smaller values as would be expected from the larger number of particles present on each sieve. The samples were one-thirty-second of the original; they were sieved by hand shaking using the 1.98 and $0.417 \mathrm{~mm}$. sieves and the tured in the trade catalog gave unsatisfactory results on a few preliminary tests. Some variations were tried without success.

A method using the scoop instead of the pan for pouring gave the best results. A kilogram, or preferably less, of the well-mixed material was carefully emptied onto the central part of the scoop and spread out somewhat, preserving about equal amounts on each side of the center line of the scoop. The scoop was then tilted gently and vibrated twice a second between the ends of the hopper until all the material on the 
scoop had passed through the splitter. It is important to keep the pouring edge at right angles to the dividing plates. The oscillation will cause the angle to vary somewhat during each vibration, but there will be less danger of introducing a bias in the percentages than if the scoop were held in a fixed position. The method is time consuming for large amounts of material. So much material of certain sizes bounced out of the pans, or did not enter, that it was collected every time and returned, lest a bias not properly chargeable to the device enter into the results. Such losses were so small on the improved splitter that the few grams recovered were returned only af ter the twelfth and twenty-fourth samples.

The sampler used in the above tests was not intended for material as coarse as commercial pea gravel and so no tests were made on the coarse mixture. There are 18 chutes just as in the improved splitter, but the chutes are only one-half inch wide. The narrower size is commonly considered preferable for such materials as the fine mixture. Perhaps the larger number of chutes usually used in the narrower sizes is the main cause of the apparent superiority.

Details of the analytical results are discussed in the second part of this paper, and supported by tables which will be referred to later.

SUMMARIZED TECHNIQUE FOR THE IMPROVED JONES SAMPLE SPLITTER

1. Pour the material to be sampled, which should be dry and free from lumps, into one of the pans. Level off the material in the pan.

2. Place a pan with lugs outward under the pouring side of the hopper and against the pan stop. Place another pan against the pan stop on the other side to receive the rejected material as shown on figure 2 .

3 . Close the covers.

4. Place the top side of the lugs of the pouring pan against the under side of the hopper rim on the lower side of the hopper as shown on figure 2 .

5. Rotate the pan using the hopper rim as a fulcrum until all the material has been emptied. Keep the lugs against the hopper rim. Tap the pan lightly with a small wood mallet if the material is dusty.

6. Exchange the now empty pan with the receiving pan, putting the lugs inward this time and repeat as before.

7. Continue until the sample has been reduced to the required size, taking care to reverse the position of the lugs each time an empty receiving pan is put in place.

In refined work on sands free from gravel, better results are obtained if the field sample is first mixed by pouring four times out of the end of one pan into the middle of another before leveling and splitting. When much gravel is present segregation appears to be increased; it is then better to empty the field sample into the middle of the pan and to pass the sample through the instrument several times.

To sample clays or silts crush the air-dried or preferably slightly damp material to pass a $2 \mathrm{~mm}$. sieve. If the crushed material is slightly damp and the covers are kept closed a half minute after each passage, dust losses will be small. Some material tends to adhere to the slides and other surfaces. Remove it by giving the splitter several sharp taps at each end on 
the metal plate surface between the three tie rods.

Whenever the quantity of material in the receiving pan is small, withdraw the pan carefully and collect the material along the bottom edge nearest the lugs. Do not allow the material to slide toward either end. If a sample has been removed from the pan and found to be too large, split off a new one the correct size; do not pass the previous sample once more through the splitter.

\section{PART II-STATISTICAL ANALYSIS OF THE DATA}

The quantitative data presented in the preceding section do not, without further study, reveal whether it is reasonable to suppose: (1) that the improved sample splitter possesses superiority over the other instrument except in convenience, speed of operation and larger capacity; (2) that the improved sample splitter can be expected to continue to give results with small dispersion; (3) that the frequency with which a value may be expected to lie within a symmetrical range of the average can be approximately predicted; (4) that the average values are not biased; (5) that some minor changes in design (without changing the basic principle) might be made which would effect a large reduction in the errors.

Careful inspection of the data yielded little information not shown by a cursory inspection. Plotting the percentages for each series on a triangular diagram revealed some differences in the distribution pattern. Plotting the sample weights against the percentages suggested relationships in some cases.

A quantitative study, based on the mathematical theory of small samples, proved to be the most effective method of analysis. Additional time required for calculation was compensated by shorter time required for locating sources of error.

The methods to be presented are applicable to any study based on samples. They furnish a new approach to the study of efficient field sampling methods. The Cooperative Laboratory has begun such a study of the field sampling of beach and dune sands for mechanical analysis. Enough has been done to demonstrate the value of the methods and of the reasoning on which they are based.

The methods and reasoning presented have been adapted from Shewhart (10); the following sections summarize some of the concepts used by Shewhart in developing his statistical techniques.

THE CONCEPT OF A STATE OF CONTROL

Let the reader write some letter of the alphabet such as $d$; now try and make 29 more as nearly alike as possible. Examine them carefully. They will not all be alike in height, width, shape, area enclosed or any one of a number of characteristics. Thus what were intended to be exact duplicates are found to possess variability when closely examined. Now let two other people repeat the experiment. Each person's $d$ 's will show differences among themselves, yet it is possible to distinguish the group made by one person from the group made by another, because each group varies within limits. The environ- 
ment under which each person produced his series of letters was controlled. The attributes or qualities of each person's $d$ 's are also said to be controlled.

If this simple experiment be repeated tomorrow, under conditions as nearly alike as possible, the variability to be expected in each person's $d$ 's can be predicted from a knowledge of the variability observed in those already made. This is the third attribute of a controlled quality. A phenomenon may be said to be controlled when its future variability can be predicted, at least within limits, from a knowledge of its past variability. Prediction within limits means that the probability that the observed phenomenon will fall within given limits can be stated approximately.

These concepts are equally applicable to the much more involved problem of taking a sample of beach sand in such a way that measurements on a series of samples taken in the same way would be controlled; or to the problem of taking a single laboratory sample for sieve analysis in such a manner that measurements on a series of similar samples would be controlled.

THE CONCEPT OF A CONSTANT

CHANCE CAUSE SYSTEM

Many measurements made in everyday work show such small fluctuations when made repeatedly that ordinarily only a single measurement is taken. Examples are the length of a rod, the weight of a metal bar or the density of a single crystal. Even here, precise determinations are subject to many errors.

Other measurements such as the density of granite determined on a series of samples from the same intrusive mass are subject to a larger relative variation. Detailed microscopic study would reveal many of the causes of variation, but there would still remain some unexplained fluctuations resulting from unknown or chance causes.

Much greater variability is ordinarily encountered in quantitative. work on sediments. Consider a series of pebble counts of the proportion of a certain kind of rock in 2-kilogram samples of gravel taken at 10-meter intervals on a gravel beach. Many variations of the proportion in the samples will remain unexplained even after a detailed study of the field conditions. If the samples are taken from a more limited area of the beach, a relatively larger amount of the variation will be unexplained. (The absolute amount of variation will usually be smaller.) Again this variation results from a complex system of unknown or chance causes.

Three postulates regarding these chance cause systems require brief consideration:

1. Some chance cause systems are such that the future can be predicted in terms of the past. On the pebble beach, if a second series of samples were taken between each of the samples in the first series, the number of samples with proportions between given limits could be approximately predicted. (Note that this is very different from saying that the 
proportion in each sample could be predicted.) However, no prediction would be expected to hold true one month later; the wind and waves constitute chance causes of such a nature that quantitative prediction is not possible. Off-shore winds might bury the pebbles beneath a layer of wind blown sand; the waves might build a sand beach over the pebble beach; a major storm might remove all the smaller pebbles and leave a cobble beach.

Statistical methods furnish a powerful tool for discovering which chance cause systems give rise to predictable phenomena.

2. Constant systems of chance causes exist in nature. The till deposited by continental ice sheets is the result of such a cause system. Despite the very complex nature of the factors or causes which determine the composition of the till at a particular location, it is possible when studying regional variations to take single samples at random from topographically comparable locations for study (6). This would not be possible if the resultant of these complex causes were not essentially constant over a considerable area.

3. Assignable causes of variation may be found and eliminated. In the development of most sampling methods, or methods of measurement, it is found that the chance cause system under which the samples are chosen or the measurements taken is not constant, because there are sometimes present certain influences or factors which can be located and eliminated.
When attempting to locate assignable causes of variation, statistical methods enable hypotheses regarding these causes to be tested and pointed out for correction.

\section{DETECTION OF LACK OF CONTROL}

The mathematics on which are based the simple arithmetical procedures for detecting lack of control cannot be described here. The methods described have been thoroughly tested and found to work, both under conditions where the basic mathematical assumptions were as nearly fulfilled as possible and in large scale manufacturing operations. Shewhart (10) describes many of these tests.

The methods developed for testing for lack of control in other laboratory measurements seem wholly applicable to a sampling study such as is here described. The use of these methods led to the detection of construction and technique defects which otherwise might have gone unnoticed in the earlier sample splitter. A number of mathematical tests were applied to the data to see if the latter conformed to the requirements of the theory; in all cases satisfactory agreement was obtained.

Two of the five tests described by Shewhart for detecting lack of control when the standard quality is unknown were used in the present studies. The first seeks to discover evidence for lack of constancy in the chance cause system; the second seeks to detect the presence of an assignable cause of variation. One test for detecting lack of control 
when a standard quality is known is also presented.

\section{TEST FOR LACK OF CONSTANCY IN THE CHANCE CAUSE SYSTEM}

It has been found that, when measurements are made on a large number of samples taken from a constant chance cause system, the measurements will vary according to a mathematical law of somewhat more general form than the so-called normal law of error (10, pp. 89-94). When only a small number of samples is available, as in the present studies, the method seeks to test the hypothesis that these samples show no more variation than could reasonably be attributed to samples coming from such a distribution.

The steps involved in making this test are given in Shewhart (10). They involve (1) listing the measurements in the order in which they were made; (2) dividing the measurements into groups of four each, starting with the first (a minimum of 8 measurements or two groups of four each are required; more dependable results are obtained with more groups); (3) computing the arithmetic mean of the four values in each of the groups; (4) computing the standard deviation, $\sigma$, of the four values in each group; (5) obtaining the average of the standard deviations of the subgroups; this value is denoted by by $\bar{\sigma} ;(6)$ computing the average of all the $X$ values, that is, the average of the means of the subgroups, which is denoted by $\bar{X}$ to distinguish it from the individual subgroup averages; (7) computing the standard error of the mean, $\sigma_{\bar{x}}$, from the formula $\sigma_{\bar{x}}=\frac{\bar{\sigma}}{c \sqrt{N}}$ where $N$ is the number of values in each subgroup and $c$ is a correction factor $^{1}$ for small samples and depends on the number of measurements in the group; (8) computing the control limits of the average by the formula $\bar{X} \pm 3 \sigma_{\bar{X}}$. A subgroup average lying outside these limits is evidence of lack of control on those factors affecting the average value and is thus evidence of lack of constancy in the chance cause system. Table I shows the data required for these calculations.

TABLE I. Summary of Calculations for Test for Lack of Control on Averages and Standard Deviations.

Shewhart's Criterion I applied to the weight percentages on the $1.98 \mathrm{~mm}$. sieve using the sample splitter shown Figure 5 .

\begin{tabular}{c|c|c}
\hline \hline Group No. & \multicolumn{1}{|c|}{$\bar{X}$} & \multicolumn{1}{|c}{$\sigma$} \\
\cline { 2 - 3 } I & 18.355 & 1.021 \\
II & 15.262 & .252 \\
III & 16.518 & 1.223 \\
IV & 16.865 & .096 \\
V & 16.580 & .796 \\
VI & 17.490 & .944 \\
\hline \multicolumn{2}{c}{ Average: $\bar{X}=16.845$} & $\bar{\sigma}=.722$ \\
\hline \multicolumn{2}{r}{}
\end{tabular}

In the above table $\bar{X}$ and $\sigma$ are computed for each consecutive group of four values by procedures found in any elementary statistics textbook. The average of both the sample means and standard deviations is then computed. The standard error of the mean, $\sigma_{\bar{X}}$, and the standard error of the standard deviation, $\sigma_{\sigma}$, are computed using the formulas given in the text. The control limits on the average are given by $\bar{X} \pm 3 \sigma_{\bar{X}}=16.85 \pm 3 \times 0.452=18.21$ and 15.49. The means of groups I and II lie

1 This factor is denoted by $c_{2}$ in the discussion on page 184 of Shewhart's book and in the table on page 185 ; this table gives the value of $c_{2}$ for samples of size $N$. 
TABLE II. Statistical summary of results obtained with the coarse material using the improved sample splitter.

\begin{tabular}{|c|c|c|c|c|c|c|c|c|c|c|c|c|}
\hline $\begin{array}{c}\text { Subject } \\
\text { Unit of Measurement }\end{array}$ & $\begin{array}{l}\text { Sample } \\
\text { Weight } \\
\text { Grams }\end{array}$ & $\begin{array}{c}\text { Gravel } \\
\text { Per Cent } \\
\text { by } \\
\text { Weight }\end{array}$ & $\begin{array}{c}\text { Granules } \\
\text { Per Cent } \\
\text { by } \\
\text { Weight }\end{array}$ & $\begin{array}{c}\text { Sand } \\
\text { Per Cent } \\
\text { by } \\
\text { Weight }\end{array}$ & $\begin{array}{l}\text { Sample } \\
\text { Weight } \\
\text { Grams }\end{array}$ & $\begin{array}{c}\text { Gravel } \\
\text { Per Cent } \\
\text { by } \\
\text { Weight }\end{array}$ & $\begin{array}{c}\text { Granules } \\
\text { Per Cent } \\
\text { by } \\
\text { Weight }\end{array}$ & $\begin{array}{c}\text { Sand } \\
\text { Per Cent } \\
\text { by } \\
\text { Weight }\end{array}$ & $\begin{array}{l}\text { Sample } \\
\text { Weight } \\
\text { Grams }\end{array}$ & $\begin{array}{c}\text { Gravel } \\
\text { Per Cent } \\
\text { by } \\
\text { Weight }\end{array}$ & $\begin{array}{c}\text { Granules } \\
\text { Per Cent } \\
\text { by } \\
\text { Weight }\end{array}$ & $\begin{array}{l}\text { Sand } \\
\text { Per Cent } \\
\text { by } \\
\text { Weight }\end{array}$ \\
\hline $\begin{array}{l}\text { Observed average } \\
\text { Expected average } \\
\text { Standard deviation }\end{array}$ & $\begin{array}{r}344.7 \\
346.8+ \\
6.6-\end{array}$ & $\begin{array}{c}48.78- \\
49.31 \\
1.16\end{array}$ & $\begin{array}{r}35.56 \\
36.45 \\
.98\end{array}$ & $\begin{array}{r}15.67 \\
14.24 \\
.41\end{array}$ & $\begin{array}{r}348.9 \\
346.7 \\
6.7\end{array}$ & $\begin{array}{r}49.79 \\
49.27 \\
1.24\end{array}$ & $\begin{array}{r}36.68 \\
36.49 \\
1.07\end{array}$ & $\begin{array}{r}13.53 \\
14.24 \\
.34-\end{array}$ & $\begin{array}{r}347.6 \\
346.0+ \\
5.3-\end{array}$ & $\begin{array}{r}49.44 \\
49.27 \\
.83-\end{array}$ & $\begin{array}{l}36.18- \\
36.49 \\
.70\end{array}$ & $\begin{array}{r}14.38 \\
14.24 \\
.46\end{array}$ \\
\hline $\begin{array}{l}\text { Control limits } \\
\text { on the average }\end{array}$ & $\begin{array}{l}351.0 \\
342.7\end{array}$ & $\begin{array}{l}50.04 \\
48.58\end{array}$ & $\begin{array}{l}37.07 \\
35.83\end{array}$ & $\begin{array}{l}14.45 \\
14.03\end{array}$ & $\begin{array}{l}350.9 \\
342.4\end{array}$ & $\begin{array}{l}50.06 \\
48.48 \\
\end{array}$ & $\begin{array}{l}37.17 \\
35.81\end{array}$ & $\begin{array}{l}14.45 \\
14.03\end{array}$ & & $\begin{array}{l}49.79 \\
48.75\end{array}$ & $\begin{array}{l}36.93 \\
36.05\end{array}$ & $\begin{array}{l}14.53 \\
13.95\end{array}$ \\
\hline $\begin{array}{c}\bar{\sigma}, 6 \text { groups of } 4 \\
\text { determinations }\end{array}$ & 5.25 & 1.04 & .82 & .33 & 4.81 & 1.05 & .87 & $.30+$ & 4.36 & .72 & .54 & .37 \\
\hline $\begin{array}{l}\text { Control limits } \\
\text { on the averages* }\end{array}$ & $\begin{array}{l}354.6- \\
334.8 \\
\end{array}$ & $\begin{array}{l}50.74 \\
46.82\end{array}$ & $\begin{array}{l}37.10 \\
34.02\end{array}$ & $\begin{array}{l}16.29 \\
15.05\end{array}$ & $\begin{array}{l}357.9 \\
339.9-\end{array}$ & $\begin{array}{l}51.77 \\
47.81\end{array}$ & $\begin{array}{l}38.31 \\
35.05\end{array}$ & $\begin{array}{l}14.10 \\
12.96\end{array}$ & & $\begin{array}{l}50.79 \\
48.09\end{array}$ & $\begin{array}{l}37.20 \\
35.16\end{array}$ & $\begin{array}{l}15.07 \\
13.69\end{array}$ \\
\hline $\begin{array}{l}\text { Control limits on the } \\
\text { standard deviations* }\end{array}$ & $\begin{array}{c}12.2 \\
0\end{array}$ & $\begin{array}{c}2.43 \\
0\end{array}$ & $\begin{array}{c}1.91 \\
0\end{array}$ & $\begin{array}{l}.77 \\
0\end{array}$ & $\begin{array}{c}11.2 \\
0\end{array}$ & $\begin{array}{c}2.46 \\
0\end{array}$ & $\begin{array}{c}2.02 \\
0\end{array}$ & $\dot{0}^{71}$ & $\begin{array}{c}10.2- \\
0\end{array}$ & $\begin{array}{c}1.67 \\
0\end{array}$ & $\begin{array}{c}1.26 \\
0\end{array}$ & $\begin{array}{l}.86 \\
0\end{array}$ \\
\hline $\begin{array}{l}\sigma / .968 N=24 \\
\sigma / .798 N=4 \\
\text { (Observed } \bar{X} \text {-true } \bar{X} \text { ) } \\
\sigma / \bar{X} \quad \sigma_{\bar{X}} \\
\end{array}$ & $\begin{array}{r}-1.6 \\
.019\end{array}$ & $\begin{array}{r}1.20 \\
1.31 \\
-2.2 \\
.024\end{array}$ & $\begin{array}{r}-4.3 \\
.028\end{array}$ & $\begin{array}{r}.43 \\
.41 \\
+16.4 \\
.026\end{array}$ & $\begin{array}{r}+1.6 \\
.019\end{array}$ & $\begin{array}{r}1.28 \\
1.32 \\
+2.0 \\
.025\end{array}$ & $\begin{array}{c}1.11 \\
1.08+ \\
+0.8 \\
.029\end{array}$ & $\begin{array}{r}-10.0 \\
.025\end{array}$ & $\begin{array}{r}5.4 \\
5.5- \\
+1.4 \\
.015\end{array}$ & $\begin{array}{r}+1.0 \\
.017\end{array}$ & $\begin{array}{r}-2.1 \\
.019\end{array}$ & $\begin{array}{r}+1.4 \\
.032\end{array}$ \\
\hline Technique & \multicolumn{4}{|c|}{$\begin{array}{l}\text { Lugs on receiving pan were placed } \\
\text { facing inward. } \\
\text { E.P. }\end{array}$} & \multicolumn{4}{|c|}{$\begin{array}{l}\text { Lugs on receiving pan were placed } \\
\text { facing outward. } \\
\text { G.O. }\end{array}$} & \multicolumn{4}{|c|}{$\begin{array}{l}\text { Lug position on receiving pan was } \\
\text { alternated each time the pan was } \\
\text { changed. } \\
\text { G.O. }\end{array}$} \\
\hline
\end{tabular}

Unless otherwise stated, all results are based on samples of 24 determinations.

* These are based on samples of 4 determinations. 
outside these limits, indicating lack of control.

Similarly, the control limits on the standard deviation are $\sigma \pm 3 \sigma_{\sigma}=.722 \pm 3 \times 0.320$ $=1.682$ and -0.238 . (Negative control limits are interpreted as zero.) Since no values of $\sigma$ lie outside these limits, no lack of control on the standard deviations is indicated.

The control limits on the standard deviation are computed in the same manner as the steps indicated above. From these computations the standard error of the standard deviation, $\sigma_{\sigma}=\frac{\bar{\sigma}}{c \sqrt{2 N}}$ is obtained when $c$ and $N$ are the same as before. In this case the control limits are $\bar{\sigma} \pm 3 \sigma_{\sigma}$. If a standard deviation of a subgroup lies outside the control limits, there is evidence of lack of control on the variability of the samples and thus lack of constancy in the chance cause system is indicated.
Three times the standard error has been used for the control limits in both cases, not so much because of the theoretical probability that 99.73 per cent of the subgroup averages and standard deviations may be expected to lie inside these limits, but because these limits have been found to be economic limits. Narrower limits would occasionally indicate trouble when it did not exist. Wider limits would fail to include many cases of lack of control. With the control limits used above there is small risk that lack of control will be indicated when it does not exist.

In computing the standard errors $\sigma / c$ is used in place of the standard deviation of the entire group of values because $\sigma / c$ is usually the smaller when the averages are not controlled; it therefore gives a more sensitive test for lack of control. When both averages and standard deviations are controlled, and a considerable number of subgroups is used, the two measures of dispersion agree very closely. In tables II and III, note the good agreement obtained with only six subgroups except for the series in which the data are not controlled.

TABLE III. Statistical summary of results obtained with the fine material.

\begin{tabular}{|c|c|c|c|c|c|c|c|c|}
\hline \multirow[b]{2}{*}{$\begin{array}{c}\text { Subject } \\
\text { Unit of Measurement }\end{array}$} & \multicolumn{4}{|c|}{ Improved Sample Splitter } & \multicolumn{4}{|c|}{ Sample Splitter Shown in Figure 5} \\
\hline & $\begin{array}{l}\text { Sample } \\
\text { Weight } \\
\text { Grams }\end{array}$ & $\left|\begin{array}{c}\text { Granules } \\
\text { Per Cent } \\
\text { by Weight }\end{array}\right|$ & $\mid \begin{array}{c}\text { Coarse } \\
\text { Sand } \\
\text { Per Cent } \\
\text { by Weight }\end{array}$ & $\left|\begin{array}{c}\text { Fine } \\
\text { Sand } \\
\text { Per Cent } \\
\text { by Weight }\end{array}\right|$ & $\begin{array}{l}\text { Sample } \\
\text { Weight } \\
\text { Grams }\end{array}$ & $\left|\begin{array}{c}\text { Granules } \\
\text { Per Cent } \\
\text { by Weight }\end{array}\right|$ & $\left|\begin{array}{c}\text { Coarse } \\
\text { Sand } \\
\text { Per Cent } \\
\text { by Weight }\end{array}\right|$ & $\begin{array}{c}\text { Fine } \\
\text { Sand } \\
\text { Per Cent } \\
\text { by Weight }\end{array}$ \\
\hline $\begin{array}{l}\text { Observed average } \\
\text { Expected average } \\
\text { Standard deviation }\end{array}$ & $\begin{array}{r}134.5 \\
134.9 \\
1.7\end{array}$ & $\begin{array}{l}16.96 \\
17.38 \\
.90+\end{array}$ & $\begin{array}{r}47.29 \\
47.61 \\
.83\end{array}$ & $\begin{array}{l}35.75 * \\
35.01 \\
.78\end{array}$ & $\begin{array}{r}138.2 \\
134.9 \\
9.8\end{array}$ & $\begin{array}{c}16.85- \\
17.41 \\
1.26\end{array}$ & $\begin{array}{r}46.78 \\
47.59 \\
1.27\end{array}$ & $\begin{array}{r}36.37 \\
35.00 \\
2.12\end{array}$ \\
\hline $\begin{array}{l}\text { Control limits } \\
\text { on the average }\end{array}$ & $\begin{array}{l}136.0 \\
133.8+\end{array}$ & $\begin{array}{l}17.95 \\
16.81\end{array}$ & $\begin{array}{l}48.14 \\
47.08\end{array}$ & $\begin{array}{l}35.50 \\
34.52\end{array}$ & $\begin{array}{l}141.0+ \\
128.7\end{array}$ & $\begin{array}{l}18.21 \\
16.61\end{array}$ & $\begin{array}{l}48.39 \\
46.79\end{array}$ & $\begin{array}{l}36.34 \\
33.66\end{array}$ \\
\hline $\begin{array}{l}\sigma, 6 \text { groups of } 4 \text { deter- } \\
\text { minations }\end{array}$ & 1.4 & $.72-$ & .70 & .56 & $8.2+$ & .72 & .73 & $.91+$ \\
\hline $\begin{array}{l}\text { Control limits on } \\
\text { averagest }\end{array}$ & $\begin{array}{l}137.1+ \\
131.9\end{array}$ & $\begin{array}{l}18.30 \\
15.62\end{array}$ & $\begin{array}{l}48.60 \\
45.98\end{array}$ & $\begin{array}{l}36.80 \\
34.70\end{array}$ & $\begin{array}{l}153.7 \\
122.7\end{array}$ & $\begin{array}{l}18.21 \\
15.49\end{array}$ & $\begin{array}{l}48.15 \\
45.41\end{array}$ & $\begin{array}{l}38.09 \\
34.65\end{array}$ \\
\hline $\begin{array}{l}\text { Control limits on } \\
\text { standard deviationst }\end{array}$ & $3 \cdot 2+$ & ${ }_{0}^{1.67}$ & ${ }_{0}^{1.63}$ & 1.30 & 19.2 & 1.68 & ${ }_{0}^{1.70+}$ & ${ }^{2} .13$ \\
\hline $\begin{array}{l}\sigma / .968, N=24 \\
\sigma / .798, N=4 \\
\text { Observed } X \text {-true } X) / \sigma_{x} \\
\sigma / X\end{array}$ & $\begin{array}{r}1.8 \\
1.7+ \\
-1.1 \\
.013\end{array}$ & $\begin{array}{r}.93 \\
-2.90- \\
.053+\end{array}$ & $\begin{array}{r}.86 \\
-1.88 \\
.018-\end{array}$ & $\begin{array}{r}.80 \\
+.70 \\
+4.5 * \\
.022 \\
\end{array}$ & $\begin{array}{r}10.1 \\
10.3+ \\
+1.6 \\
.071\end{array}$ & $\begin{array}{r}1.30 \\
.90+ \\
-2.1 \\
.075\end{array}$ & $\begin{array}{r}1.31 \\
-3.92 \\
.027\end{array}$ & $\begin{array}{r}2.19 \\
1.14 \\
+3.1 \\
.058 \\
\end{array}$ \\
\hline $\begin{array}{l}\text { Technique } \\
\text { Operator }\end{array}$ & \multicolumn{4}{|c|}{$\begin{array}{l}\text { Lugs on receiving pan were placed facing } \\
\text { outward. } \\
\text { E.P. }\end{array}$} & \multicolumn{4}{|c|}{$\begin{array}{l}\text { Scoop was used for pouring as described } \\
\text { in text. } \\
\text { Runs } 1-20 \text { : L.Z. Runs } 21-24 \text { : E.P. }\end{array}$} \\
\hline
\end{tabular}

* This bias could be eliminated by alternating the receiving pan position each time the pan is interchanged.

Unless otherwise stated, all results are based on samples of twenty-four determinations.

+ These are based on samples of 4 determinations. 
TEST FOR LACK OF CONTROL IN RESPECT TO STANDARD QUALITY

For each of the two mixtures studied, the average sample weight which should be obtained is known; also, the actual percentages retained on each of the two sieves are accurately known. These values, then, furnish a standard of quality by which the performance of the sample splitter may be measured. If the average of a series of $N$ determinations differs from the true or expected value by an amount which is greater than could reasonably be attributed to random sampling fluctuations, the fact is taken as evidence of lack of control.

A different standard error of the mean is employed. This time, only one group of 24 measurements is available for its estimation. (In the previous test, six groups of four determinations each were available.) The standard error of the mean is the standard deviation of a frequency distribution of averages of samples of size N. Suppose that a large number of groups of 24 measurements each is obtained and the average value is determined for each group. The standard deviation of these averages is the standard error of the mean. Ordinarily it is estimated from the value of a single group. This estimate occasionally may be quite far from the true value, but the chances are large that it is close enough to be serviceable. An estimate based on a sample of 25 or more measurements possessing a low ratio of standard deviation to average value is reliable for most work.
The first two series using the coarse mixture were run in such a way that the standard deviations should remain essentially unchanged. The changes in technique should affect mainly the direction of sign in the bias. Note the stability in the corresponding standard errors for coarse material.

Lugs fac-

Sample Pea Granules Sand

ing in-

ward
Lugs fac-

ing out-

$\begin{array}{lllll}\text { ward } & 1.42 \mathrm{~g} . & .262 \% & .226 \% & .071 \%\end{array}$

Several factors cause the bias, but in the present case the most important seems to be the following. Refer to the upper drawing on figure 2 ; note that only the receiving pan is shown and that an abnormal fraction enters the receiving pan at the left side and the reject pan at the right side. Because of frictional drag on the sides, the smaller grains tend to get into these abnormal fractions. It follows that the coarser particles which were along the the sides tend to get moved over to the next chute. Because the same process happens at both ends of the pouring pan, the contents of the reject and receiving pans have the same average composition after the first passage. If the receiving pan contents are now emptied into the hopper without changing the orientation, the right hand side, which has just been shown to contain too much coarse material is now lost to the reject pan. The average composition in the receiving pan is now too high in fines and will continue to become more biased as the subdivision is continued.

If the receiving pan lugs are facing outward at the start, the pan will have to be turned each time, and the fine end will be lost to the reject pan.

When the lug positions are alternated, a compromise is effected. The two errors of opposite sign nearly compensate each other. Brunton (3) seems to have had this explanation in mind when discussing the bias usually present in a series of Jones sample splitters arranged in tandem. 
When the quantity of coarse material is small as in the fine mixture, the error just described is much less important. In such a case, it seems that accidental variations in width of chutes and the shape of the hopper end plates are the major sources of error. Here again, reversing the pan positions will tend to compensate these errors.

The actual computation of the control limits is done essentially as in the other test. The true mean is used in place of the observed value; the standard deviation of the entire set of measurements is used. The value of the correction factor for small samples is changed to suit the larger size of $\mathrm{N}$.

If the observed average value lies outside these limits, there is evidence for lack of control; such a condition indicates bias in the sample splitter and may result from defective design or construction or from defective technique of operation.

When it is desired to compare the bias in a series of values it is preferable to determine the ratio of the difference between the observed and expected averages to the standard error of the mean. The calculations are shown below, assuming that the average and standard deviation of the group have been calculated.

$$
\begin{aligned}
0.336 \%= & \sigma \quad \text { (standard deviation } \\
& \text { of the } 24 \text { values). } \\
14.24 \%= & \text { true percentage of ma- } \\
& \text { terial passing the } .991 \\
& \text { mm. sieve. } \\
13.53 \%= & \text { observed mean. } \\
0.968= & \text { correction factor for } \\
& \text { sample size of } 24 . \\
\sigma_{\bar{X}}= & \frac{.336}{.968 \quad \sqrt{24}} \\
= & (.211)(.336)=.071
\end{aligned}
$$

$$
\begin{aligned}
& \frac{\text { observed mean-true mean }}{\sigma_{\bar{X}}}= \\
& \frac{13.53-14.24}{.071}=\frac{-.71}{.071}=-10
\end{aligned}
$$

Since the ratio is far outside the range \pm 3 , bias is indicated beyond question. Tables II and III show the ratio (observed mean-true mean) $/ \sigma_{\bar{X}}$, for the determinations on both the coarse and fine material.

\section{TEST FOR THE PRESENCE OF AN ASSIGNABLE CAUSE OF VARIATION}

Two methods for detecting an assignable cause of variation were used. In the first, some change was made in a detail of design or operation and a new series of measurements was made. The tests previously described were applied to the data to see if the bias had been removed and if the data were otherwise controlled. The standard deviations were also compared. More refined methods of study gave little additional information of practical use. This first method requires that a possible cause of variation be known.

The second method may be applied without such knowledge whenever two or more measurements have been made on each of a series of samples. If the data have previously shown lack of constancy in the chance cause system, the test cannot be interpreted literally, since it involves the correlation coefficient, ${ }^{1}$ use of which is valid only when the data are known to have some from an approximately

1 The reader is referred to any standard textbook of statistics for a full discussion of the correlation coefficient. 
normal distribution. However, when the data come from a constant chance cause system, it is quite probable that they also come from such a distribution. A further check was made on the validity of using the correlation coefficient in the present study: the individual measurements on weights and percentages from which table IV was calculated were ranked according to size. From the standard deviation of the group and the observed average, the limiting values were calculated corresponding to the probable error and one, two and three standard deviations. When the data were controlled, the number of values falling inside these limits was in all cases close to the theoretical number.

The usual simple formulas for interpreting the correlation coefficient were not intended for as few as 24 pairs of observations. Fisher (5) developed a transformation for such cases, in which a new value $z$ was found in terms of the correlation coefficient $r$. The value of $z$ may be obtained from a short table of hyperbolic tangents such as that by Peirce (8). If, as Shewhart (10) has shown, the value of $\approx$ lies outside the limits $\pm \frac{3}{\sqrt{N-3}}$, the presence of a cause of variation simultaneously affecting both variables is indicated.

TABLE IV. Transformed correlation coefficients. $z=\tanh ^{-1}(r)$

\begin{tabular}{|c|c|c|c|c|}
\hline \multicolumn{5}{|c|}{ Coarse Material } \\
\hline Method & $\begin{array}{l}\text { Variables } \\
\text { Correlated }\end{array}$ & Gravel & Granules & Sand \\
\hline $\begin{array}{l}\text { Lugs on receiving pan were placed } \\
\text { facing inward. }\end{array}$ & $\begin{array}{l}\text { Sample weight } \\
\text { Gravel } \\
\text { Granules }\end{array}$ & $+1.11^{*}$ & $\begin{array}{l}-.90 \\
-1.72\end{array}$ & $\begin{array}{l}-.62 \\
-\quad .64 \\
+\quad .25\end{array}$ \\
\hline $\begin{array}{l}\text { Lugs on receiving pan were placed } \\
\text { facing outward. }\end{array}$ & $\begin{array}{l}\text { Sample weight } \\
\text { Gravel } \\
\text { Granules }\end{array}$ & +.66 & $\begin{array}{l}-.56 \\
-2.06\end{array}$ & $\begin{array}{l}-\quad .56 \\
-\quad .70 \\
+\quad .40\end{array}$ \\
\hline $\begin{array}{l}\text { Lug position on receiving pan was } \\
\text { alternated each time the pan was } \\
\text { changed. }\end{array}$ & $\begin{array}{l}\text { Sample weight } \\
\text { Gravel } \\
\text { Granules }\end{array}$ & +.45 & $\begin{array}{l}-.38 \\
-1.20\end{array}$ & $\begin{array}{l}-.22 \\
-\quad .60 \\
-\quad .02\end{array}$ \\
\hline
\end{tabular}

Fine Material

\begin{tabular}{|c|c|c|c|c|}
\hline Method & $\begin{array}{l}\text { Variables } \\
\text { Correlated }\end{array}$ & Granules & $\begin{array}{l}\text { Coarse } \\
\text { Sand }\end{array}$ & $\begin{array}{l}\text { Fine } \\
\text { Sand }\end{array}$ \\
\hline $\begin{array}{l}\text { Lugs on receiving pan were placed } \\
\text { facing outward. }\end{array}$ & $\begin{array}{l}\text { Sample weight } \\
\text { Granules } \\
\text { Coarse sand }\end{array}$ & +.48 & $\begin{array}{l}+.01 \\
-.70\end{array}$ & $\begin{array}{l}-.60 \\
-\quad .57 \\
-\quad .39\end{array}$ \\
\hline $\begin{array}{l}\text { Sample splitter shown in fig. } 5 \\
\text { was used as described in text. }\end{array}$ & $\begin{array}{l}\text { Sample weight } \\
\text { Granules } \\
\text { Coarse sand }\end{array}$ & $+.04 \dagger$ & $\begin{array}{l}+\quad .14 \\
+\quad .43\end{array}$ & $\begin{array}{l}-.11 \\
-1.21 \\
-1.22\end{array}$ \\
\hline
\end{tabular}

* Values of z outside the limits \pm 0.65 are probably significant.

$\dagger$ These correlation coefficients have only a qualitative significance. 
The method does not tell what the cause is; it does tell something important about the cause. Before the test was applied it was not possible to state whether such a cause group even existed. Table IV gives the transformed correlation coefficients.

\section{STATISTICAL BASIS FOR IM- \\ PROVEMENTS IN DESIGN}

An earlier design of the improved sample splitter sought to eliminate the personal element in the operation and to increase the allowable size of material which could be sampled. The statistical analysis of the data from the earlier form showed beyond reasonable doubt that there were causes of variation which could be eliminated if only they could be found. This was the most important result obtained. The experiments on hopper design were conducted using only sample weights to indicate the presence of trouble. The first two tests for lack of control were applied. The changes in the standard deviation were noted for each modification of the technique or design. These studies indicated that better results would be obtained with a low hopper.

It was decided at the outset of the tests on the final improved sample splitter that the percentages actually present ought to be known, since ordinary observations on the other instrument showed a preferential loss of certain sizes of particles to one side of the splitter. The present mixtures were planned to make it especially difficult to obtain accurate samples by introducing two discontinuities in the size frequency distribution and making the mixture trimodal.

The tests on the final splitter were begun on the coarse mixture with the lugs of the receiving pan facing inward just as a matter of convenience. Statistical analysis of these data showed a large bias in the average percentage in the pan. It was also found that the percentages on the coarse sieve were correlated with those on the sieve just beneath despite the absence of sieving errors. The sample weights were also correlated with the amount of the two coarser sizes present. The high correlation coefficients were interpreted to mean that some factor affected only the amount of coarse material.

A new series was then run with the receiving pan lugs facing outward. The bias was still present, but reversed in sign. The fact that many other statistics changed little confirmed the opinion that determinations on 24 samples were sufficient to give stable values, despite the fact that this second series was done by a different operator.

In addition to the statistical study previously made, a similar study was carried out for three weight ratios: weight of pea gravel to weight of granules, weight of granules to sand, and weight of pea gravel to sand. An analogous but less pronounced bias was still present. The ratios showed no indication of lack of constancy in the chance cause system from which they were derived. The correlation coefficients were generally lower. Insofar as could be ascertained, a study of the ratios seemed to afford a less sensitive indication of trouble than a study of the actual percentages and was therefore discontinued. Furthermore, it was difficult to get a physical picture for many of the correlation coefficients.

A comparison of the first two groups of correlation coefficients given in table IV shows that the first group, in which the receiving pan lugs were facing inward, consistently has larger values for the coefficients involving the sample weight, and smaller values for the coefficients between the percentages themselves. These differences, unlike those of the bias, seem to result mainly from differences in the rate of pouring; the lug position is probably a factor of secondary importance operating in the same direction. The samples for the second group were obtained with a faster pouring rate than was used for the first group. Studies made on the earlier form of sample splitter indicate that in general high pouring rates tend to decrease bias caused by the technique or construction of the instrument, to increase the standard deviations of the sample weights and percentages and to decrease correlations of percentages with sample weights. These principles are found to apply here, but it must be emphasized that the important reversals of the sign of the bias are solely the result of the receiving pan orientation.

In obtaining the samples of the third se- 
ries, in which the pan lug positions were alternated, a moderately fast pouring rate was used. In accordance with expectations the bias was completely eliminated, all the correlation coefficients showed a decrease and only one significant value remained; this was noticeably lower than before. Three of the four ranges and three of the four standard deviations were reduced by substantial amounts. All the evidence showed that a state of control was being approached. Further investigation was considered unnecessary.

It has been observed in manufacturing studies that, as a state of control is approached, the variability in the product diminishes; it has also been noticed, that, after thorough statistical tests have shown no evidence of lack of control, further reduction in the variability of the product will be effected only by basic changes in design or operation.

The application of the latter principle to the one remaining evidence for lack of control leads to the conclusion that there is still room for some improvement without changing the basic design. A number of other tests for detecting lack of control were not applied, largely because of the paucity of measurements. These might indicate additional assignable causes of variation.

In order to afford the interested reader a detailed demonstration of the results obtained with the improved sample splitter, table $\mathrm{V}$ is given here. It includes data on the 24 sieve tests made with the coarse mixture and indicates that the theoretical values and observed results agree quite closely.

TABLE V. Results obtained with improved sample splitter.

\begin{tabular}{|c|c|c|c|c|}
\hline Run No. & $\begin{array}{l}\text { Sample } \\
\text { Weight } \\
\text { in Grams }\end{array}$ & $\begin{array}{c}\text { Per Cent } \\
\text { by Weight } \\
\text { on } 3.33 \mathrm{~mm} \text {. } \\
\text { Sieve }\end{array}$ & $\begin{array}{l}\text { Per Cent } \\
\text { by Weight } \\
\text { on } .991 \mathrm{~mm} . \\
\text { Sieve }\end{array}$ & $\begin{array}{l}\text { Per Cent } \\
\text { by Weight } \\
\text { in Pan }\end{array}$ \\
\hline $\begin{array}{r}1 \\
2 \\
3 \\
4 \\
5 \\
6 \\
7 \\
8 \\
9 \\
10 \\
11 \\
12 \\
13 \\
14 \\
15 \\
16 \\
17 \\
18 \\
19 \\
20 \\
21 \\
22 \\
23 \\
24\end{array}$ & $\begin{array}{l}350.1 \\
346.6 \\
346.9 \\
346.7 \\
338.5 \\
344.9 \\
353.5 \\
356.8 \\
346.4 \\
348.9 \\
339.8 \\
350.0 \\
349.9 \\
350.2 \\
338.4 \\
354.1 \\
353.2 \\
352.1 \\
346.3 \\
353.8 \\
341.1 \\
338.3 \\
350.8 \\
345.1\end{array}$ & $\begin{array}{l}49.17 \\
48.32 \\
49.76 \\
50.33 \\
49.11 \\
50.92 \\
48.57 \\
49.79 \\
49.12 \\
49.76 \\
49.52 \\
50.12 \\
50.23 \\
49.40 \\
48.29 \\
49.38 \\
50.11 \\
49.70 \\
49.19 \\
50.50 \\
49.39 \\
46.91 \\
49.20 \\
49.87\end{array}$ & $\begin{array}{l}36.97 \\
37.31 \\
36.24 \\
36.23 \\
36.36 \\
35.37 \\
36.64 \\
36.08 \\
35.81 \\
35.59 \\
36.25 \\
35.62 \\
34.53 \\
36.10 \\
36.58 \\
36.37 \\
35.52 \\
35.50 \\
36.47 \\
35.86 \\
36.24 \\
38.15 \\
36.49 \\
35.96\end{array}$ & $\begin{array}{l}13.85 \\
14.37 \\
14.00 \\
13.44 \\
14.53 \\
13.71 \\
14.79 \\
14.13 \\
15.07 \\
14.65 \\
14.23 \\
14.26 \\
15.24 \\
14.50 \\
15.13 \\
14.25 \\
14.37 \\
14.80 \\
14.34 \\
13.63 \\
14.37 \\
14.94 \\
14.31 \\
14.17\end{array}$ \\
\hline \begin{tabular}{l}
\multicolumn{1}{c}{ Component } \\
Average \\
Expected average \\
Difference
\end{tabular} & $\begin{array}{r}347.6 \\
346.0 \\
+1.6\end{array}$ & $\begin{array}{l}\text { Pea gravel } \\
49.44 \\
49.27 \\
\quad+.18\end{array}$ & $\begin{array}{c}\text { Granules } \\
36.18 \\
36.49 \\
-.31\end{array}$ & $\begin{array}{l}\text { Sand } \\
14.38 \\
14.24 \\
+.14\end{array}$ \\
\hline Method & \multicolumn{4}{|c|}{$\begin{array}{l}\text { Lug position on receiving pan was alternated each time the pan was } \\
\text { changed. }\end{array}$} \\
\hline
\end{tabular}


SUMMARY

An improved sample splitter for laboratory use has been described. It was compared with a good commercially obtainable instrument and found to be superior in the following ways:

1. It is faster to operate, will handle coarser material, and has a larger capacity; there is no sacrifice of dependability when the samples are small.

2. The samples obtained with this improved splitter are free from occasional erratic samples.

3. A large reduction in the variability of the samples was obtained with the improved splitter, even when an inferior technique was used.

4. Different operators, without previous experience, can obtain comparable results.

5. No special skill or training is necessary for even the most efficient mode of operation.

The concept of a state of control and the concept of a constant chance cause system were discussed in their relation to geological sampling problems.

Methods for detecting lack of con- trol in a series of samples were explained in terms of (1) the detection of a lack of constancy in the chance cause system under which the samples were taken; (2) detection of a significant variation of the average of a series of measurements from some standard value or quality; (3) detection of an assignable cause of variability.

The application of these methods led to final improvements in design and technique by pointing out the unsuspected existence of a lack of control and occasional erratic results in the earlier form of the splitter.

The writer wishes to acknowledge assistance from Dr. R. T. Knapp who contributed a detail of the design, and Messrs. H. Kurihari, D. Luckenbill, E. Porter and L. Zuckerman who did much of the laboratory work and routine calculations. J. Hough made suggestions regarding the tests on the commercial sample splitter, and E. Porter made suggestions regarding technique for the improved splitter. Professors I. Campbell, W. Houston and H. Gilbert of the California Institute of Technology read and criticized the manuscript.

\section{BIBLIOGRAPHY}

1. Argall, Philip, Sampling and dry crushing in Colorado: Inst. Min. Metallurgy, Trans., vol. 10 , pp. $234-299,1902$.

2. Brunton, D. W., A new system of ore sampling: Am. Inst. Min. Met. Eng., Trans., vol. 13, pp. $639-645,1885$.

3. $\frac{}{567-59}$, Modern practice of ore sampling: Am. Inst. Min. Met. Eng., Trans., vol. 40, pp. $567-596,1909$.

4. $\frac{}{2}$, The theory and practice of ore sampling: Am. Inst. Min. Met. Eng., Trans., vol. 25, pp. 826-844, 1895 .

5. FISHER, R. A., Statistical methods for research workers, second ed. Oliver and Boyd, London, pp. $163-177,1928$.

6. Krumbern, W. C., Textural and lithological variations in glacial till, Jour. Geology, vol. 41, pp. 382-408, 1933.

7. Peele, Robert, editor, Mining Engineers' Handbook, John Wiley and Sons, New York, pp. 1732-1737, 1918. 
8. Peirce, B. O., A short table of integrals, third revised ed., Ginn and Co., Boston, 1929.

9. Rickard, T. A., editor, The sampling and estimation of ore in a mine, Eng. and Min. Jour., New York, pp. 107-110, 1906.

10. Shewhart, W. A., Economic control of quality of manufactured product, D. Van Nostrand Co., 1931.

11. Wentworth, C. K., A scale of grade and class terms for clastic sediments: Jour. Geology, vol. 30 , pp. $377-392,1922$.

12. - Methods of mechanical analysis of sediments: Univ. Iowa, Studies in Nat. Hist., vol. 11, pp. 29-32 and pp. 44-46, 1926.

13. - , The accuracy of mechanical analysis: Am. Jour. Sci., vol. 13, pp. 399-408, 1927. 